\title{
NARRATIVE SOVEREIGNTY, EMOTIONS AND INTERSPECIES RELATIONSHIPS
}

\author{
Rowena Lennox | University of Technology Sydney
}

\begin{abstract}
This article engages the claim that narrative is crucial to humans' capacity to imagine and to know other animals. It brings together the concept of political sovereignty from Derrida, with an evaluation of emotion to analyse narratives about interspecies relationships. I begin by mapping Derrida's critique of the relationship between violence and scientific knowledge about animals (Derrida 2009: 276-304) onto recent research into relationships between people and dingoes on K'gari (Fraser Island), to delineate how violent epistemologies may underpin humans' ways of knowing other animals. I then explore the politics of the public education about dingoes on K'gari as they relate to government policies and the way the state exercises power; such state-sanctioned narratives set the discursive tone for the way people know and interact with (this) other species, and disallow other epistemologies. In contrast, creative nonfiction narrators Barry Lopez (Of Wolves and Men, 2004) and Helen Macdonald ( $H$ Is for Hawk, 2014) perform their own critiques of inaccurate and controlling narratives about, respectively, wolves and goshawks. I argue that the techniques they use-acknowledging emotion; observing animals' perceptions, relationships and agency; respecting animals' ability to resist human-imposed meanings; recognising the limits of human knowledge; and incorporating other voices-provide a framework for how creative writers may narrate other animals more ethically and more accurately.
\end{abstract}

\section{BIOGRAPHICAL NOTE}

Rowena Lennox is an adjunct fellow at the Centre for Public History at UTS and co-investigator, with Professor Fiona Probyn-Rapsey at the University of Wollongong, on research into the use of dingoes implanted with poison 1080 capsules to eradicate goats from Pelorus Island in Queensland. Rowena's essays, fiction and poems have been widely published and her first book, Fighting Spirit of East 
Timor (2000), won a NSW Premier's History Award in 2001. In 2019 she completed a doctorate of creative arts at UTS and her second book, Bold: ingenious dingoes of K'gari, based on her doctoral research into emotional relationships between people and dingoes, is forthcoming with Sydney University Press in 2020.

KEYWORDS

Narrative sovereignty-Emotions-Dingoes-Human-animal relationships-Creative non-fiction

Narrative can be defined as a communication process in which an event or succession of events are described by an addresser or narrator to an addressee or audience or readers (Rimmon-Kenan 1983: 2-3). Necessarily, narrative orders and hierarchises knowledge and experience. Narrators appear to see and know all, or all that is relevant, or as much as they can. Narrators distil, judge (consciously or otherwise), and decide what to show their readers and the order in which to show it. With this in mind, I wish to explore the idea of the narrator's control over the narrative being arguably akin to that of a sovereign over their subjects. In the concept of political sovereignty, developed since the sixteenth century by European thinkers including Niccolò Machiavelli, Jean Bodin, Thomas Hobbes and Carl Schmitt, the sovereign makes laws but is not subject to them; sovereignty is absolute and indivisible, it cannot be shared. The sovereign also has the ability to see without being seen. The sovereign's absolute power is contested and is, of course, a fiction (Keane 2014; Wadiwel 2010: 4). Sovereignty, and the sovereign, according to Derrida (2009: 289), need representation or narrative to maintain and transmit power. Hence, narrative becomes 'a structural part of sovereignty'; narrative allows readers to feel as if they too preside over the events and destiny of the characters they read about; readers have the illusion of 'knowing everything in advance, of sharing absolute knowledge with the king' (Derrida 2009: 289).

The power of narrative and its relationship to political sovereignty are salient to the representation of a sometimes-maligned and often misunderstood species: the dingo. For the past several years, I have been researching and writing creative non-fiction about emotional relationships between people and dingoes as part of a doctorate of creative arts (Lennox 2013a; 2013b; 2014; 2016; 2017). My fieldwork took me to Fraser Island, known as K'gari to its traditional custodians, the Butchulla people. An estimated population of between 76 and 171 dingoes live in nineteen family groups on K'gari (Allen et al. 2015) in places they have inhabited for generations. Although only about 
200 people live on the island permanently, about 400,000 tourists visit every year. Some of the dingoes' territories are heavily frequented by people. The staff of Queensland Parks and Wildlife Service (QPWS) manage most of K'gari, and implement the Fraser Island Dingo Conservation and Risk Management Strategy (FIDCRMS) (Ecosure 2013), which aims to ensure that visitors have a 'wildlife experience' by conserving a sustainable wild dingo population while minimising risks to human safety and dingo welfare.

One afternoon in May 2015, while I stood on K'gari's eastern beach photographing dingo paw prints on the sand, a young dingo approached me. He came close, looked up at my face, half-circled me, sniffed my leg, came around to face me again and looked into my eyes before, after the split-second beginnings of a play-bow, he walked away. I stood still. My companion-a longtime dingo researcher and photographer whom I was interviewing for my doctoral research-photographed our one-minute interaction. Over the next three months this dingo approached many more people. In August, after his second report for nipping a person, he was killed by QPWS staff because he was deemed to pose a safety risk to people. As is routine, a veterinarian and QPWS staff performed a necropsy on his body. The necropsy revealed that he was a healthy dingo in good condition, whose spleen was round and swollen from barbiturate use. QPWS staff used a barbiturate called pentobarbitone sodium to kill him. The necropsy did not reveal what made him so interested in people.

In a lecture on the optics of sovereignty that brings together King Louis XIV of France, the ceremonial dissection of an elephant and the scientists who performed the dissection in front of the king in 1681, Derrida shows how the autopsy ushers in a new era of scientific knowledge. In Derrida's analysis, the autopsy is primarily an 'optical experience that aims to touch with the eyes what falls under the hand, under the scalpel' (Derrida 2009: 277). It is a way of knowing, an epistemic resource that, like narrative, is 'never a stranger to that of power' (Derrida 2009: 279, italics in original). The order of knowledge produced by the autopsy is 'free and all-powerful ... sure of power [with] possession and mastery over its object' (Derrida 2009: 280). Zoology and biology, the rational discourses that pertain to animality or bestiality, Derrida argues, are based on the violence of the 'becoming-object' of the living elephant (Derrida 2009: 279, 277). This power imbalance pertains to scientific representations of animals in an ongoing way, into the decade following Derrida's lecture on the autopsy and sovereignty.

While emotion is not usually considered to be part of traditional scientific discourse, in this essay I argue that science-based, as well as creative nonfiction animal narratives, are unavoidably full of implicit and explicit emotions. Scientific narratives transmit emotional messages to their audiences that affect humans' relationships with animals; they are not exempt from emotional content. In the case of the dingoes of K'gari, concepts of sovereignty, involving control over territory, and behaviourist theories underpin implicit emotional messages in official narratives. But representing animals as objects, to be disposed of in the manner of the autopsy, or as simple automatons, motivated 
by the most base needs, fails to take into account animal preferences and animal agency, and limits what humans are able to observe and imagine about other animals.

K'gari's dingoes

On K'gari, public education about dingoes adopts a specific emotional position toward dingoes and arguably prompts curated emotional reactions in its addressees or audiences. Although the Queensland government invokes the authority of science when it claims that ' $[\mathrm{t}] \mathrm{he}$ Fraser Island Dingo Conservation and Risk Management Strategy has been prepared with expert input and is implemented by a team guided by qualified scientists who are wildlife experts in their own right' (Queensland government 2014), so-called scientific research into dingoes and narratives about dingoes have long been skewed by human political agendas, including race, alongside colonial, agricultural and commercial interests (Rose 2000; 2011; Parker 2006; Probyn-Rapsey 2015; Lennox 2017; 2019a; forthcoming). My contention is that even the disputed scientific names for the dingo can be read as an attempt to describe dingoes' prehistoric genealogy and reflect settler Australians' anxieties about miscegenation and racial purity, as well as ontological uncertainties about what dingoes are and how they came to be in Australia. One name, Canis lupus dingo, describes the dingo as a subspecies of the wolf. Another, Canis familiaris dingo, denotes that the dingo is a subspecies of the domestic dog (Canis familiaris), meaning that it was once domesticated but is now feral, an invasive animal, a pest. The third, like the other two, is not without its controversies: Canis dingo describes the dingo not as a dog or as a wolf, but as itself, unique-though some conservation biologists and dingo geneticists use this term as a designation of the genetic purity of some dingoes.

The QPWS narrative about dingoes-disseminated through dingo-education publications and signage, and online (Queensland government 2014)-claims to be objective and empirically based. Dingoes are described in terms of biological life cycles and natural selection. According to the FIDCRMS, and notably for the purposes of the argument in this article, dingoes' sociability with or curiosity about humans is motivated primarily by food. They are seen through the lens of outdated behaviourist theories that describe animals as automatons 'for whom understanding is limited to simple associations' (Despret 2016: 319). Dingoes fed by humans, according to the FIDCRMS, become altered, 'habituated'; they no longer act in a truly wild way, which, in QPWS's definition, means staying away from people (Ecosure 2012: 78). In this paradigm dingoes must comply with human-determined 'species-typical behaviour' regarding 'wildness' (Donaldson and Kymlicka 2016: 2). So some behaviours-such as approaching and trying to communicate with people; inspecting (and sometimes breaking or taking) people's possessions including tents, coolers, cameras and fishing gear; eating people's food; and walking 
through, standing, lying, sitting and playing in camping zones and busy areas of the beach-are described in QPWS reports as 'loitering', 'soliciting' and 'stealing' (Queensland government 2017-2018) - that is, acts of delinquency, as Foucault theorises (1995: 277). Although this behaviour is prohibited, some dingoes continue to show interest in people and their things. Conflict with people ensues and dingoes involved with 'high-risk' interactions with people are killed (Queensland government 2017-2018).

The optics of sovereignty form part of official constructions of dingo-human relationships on K'gari. QPWS exercises a sovereign gaze over the island with trail cameras set up in many places, so that people, dingoes and other wildlife are under surveillance. On the barge from Inskip Point (on the mainland) to Hook Point (on the southern tip of the island), educational signs emphasise how dangerous dingoes can be and provide information about how to keep food away from them because '[d]ingoes that get their food from people may become aggressive'. People are advised always to walk in pairs or groups, never to approach a dingo, and never to go bush toileting alone-'take someone with you to watch for dingoes'. The signs evoke an all-seeing dingo, when they ask, 'Who is watching your behaviour?' Another in this series tells anglers to use tightly sealed containers in a vehicle or shoulder bag for fish catch, bait and berley; never to clean fish at campsites, townships or other prohibited sites, and to bury offal at least fifty centimetres deep and just below the high tide mark. 'Who is watching your catch and bait?' the sign asks. 'You should be.' The dingoes invoked by these signs are able to see, hear and smell people when people are not aware of their presence. Surveillance-the ability to see without being seen-is part of the sovereign's power. Humans assume they must be sovereign in an environment such as K'gari. But the signs show how sovereign dingoes might subvert the assumption of human sovereignty, and emphasise that such subversions involve risks to human safety.

Official signage and education about K'gari's dingoes purports to be objective but these texts oversimplify dingo behaviour, and characterise dingoes as dangerous and threatening. Like other narratives, this narrative leaves traces and inculcates emotional responses in its audience; in this case the emotion is fear. This narrative dominates the way people interact with dingoes and disallows other narratives. It omits accounts of dingo sociality, family dynamics and how dingo families (or packs) have adapted to human-made changes on the island, such as fences and cattle grids, designed to keep them out of places they once frequented. It does not admit that close observation reveals nuance, dynamism and complexity in dingo agency. For the creative work of my doctoral thesis, I interviewed five people personally and professionally connected to the island's dingoes. Sovereignty plays a role in their understandings of dingodingo relations. Interview participants described different ways dingo sovereignty over territory is negotiated and enacted: dingoes from different territories share resources (such as a lake on the boundary of two packs' territories) and chase away dingoes from other packs who enter their territory (Parkhurst 2015); dingoes fight with other dingoes-sometimes to the death- 
to defend or to occupy territory (Dwyer 2015; Novak 2015; Skelly 2015); sometimes, dingoes must cede territory to younger dingoes and walk long distances to find a different place to live (Behrendorff 2015; Behrendorff and Allen 2016). Interview participants described feedback loops in dingo-human interactions: how dingoes react to people's actions and how people react to dingo's actions result in different outcomes (Behrendorff 2015). Under Queensland's Nature Conservation Act (1992), dingoes are meant to be protected on K'gari; they are part of the biological processes that give the island its World Heritage status, but they are routinely killed for behaving like dingoes.

Although QPWS have begun to acknowledge the longstanding relationships between the Butchulla people and their dingoes (QPWS 2017), relationships between people and dingoes on K'gari are effectively prohibited (Carter et al. 2017). Aboriginal Australians' relationships with dingoes are different from settler Australians' relationships with them. Women breastfed dingo pups (Philip 2017: 86) and carried dingoes to keep their backs warm (Hamilton 1972: 293). In the ethnographic record, dingoes are more consistently associated with women's foraging expeditions than men's hunting (Balme and O'Connor 2016: 778). Many Indigenous languages, including Butchulla, distinguish wild dingoes who do not live with people (wongari in Butchulla) from tame dingoes who have close relationships with people (wat'dha in Butchulla) (QPWS 2017: 2)-though under the FIDCRMS, all dingoes on K'gari must be treated as wongari now.

Barry Lopez's wolves, Helen Macdonald's goshawk

To contest this oversimplified scientistic narrative about dingoes is, I'd contend, to contest a particular kind of narrative sovereignty with implications for a species that has had close, kin-like relationships with humans for at least a millennium. In this section, I analyse two narratives that are sensitive to nuances of animals' perceptions and agency as examples of how creative writers might narrate interspecies relationships more ethically and more accurately. Barry Lopez's Of wolves and men blends natural history, science, Indigenous knowledge and Western folklore to think about the 'potent' symbolism and metaphor of wolf imagery (Lopez 2004: 226). Lopez's distrust of science is explicit. He rejects 'the arrogant claims of science to objectivity' (Lopez 2004: 224), especially in relation to wolves: 'It is hard to conceive of another animal - I don't think there is one - that has suffered such prejudice as an object of our scientific curiosity' (Lopez 2004: 224). Treating an animal as 'an object to be quantified' limits rather than expands knowledge (Lopez 2004: 77-8): 'we do not know very much at all about animals. We cannot understand them except in terms of our own needs and experiences. And to approach them solely in terms of the Western imagination is, really, to deny the animal' (Lopez 2004: 86). Nevertheless, he values empirical observation and, he writes, the way 
modern hunters, the Nunamiut Inuit, observe wolves as part of the universe, reflects a different more holistic knowledge that allows the wolf mystery and agency. 'Some things are known, other things are hidden ... Their knowledge is precise but open-ended' (Lopez 2004: 80-1). Nunamiut observers recognise that 'social animals evolve, that what you learn today may not apply tomorrow, that in striving to create a generalized static animal you have lost the real, dynamic animal' (Lopez 2004: 81).

Lopez's view of the wolf is long and expansive, but it starts close up when he asks his readers to imagine a three-year-old male wolf travelling through the Rockies in northern Canada in early September (Lopez 2004: 9-12). He draws on diverse sources to create a picture of how this wolf moves: trotting along with a pine cone in his mouth, 'head erect, tail erect, his hips slightly to one side and out of line with his shoulders, as though hindquarters were impatient with forequarters' (Lopez 2004: 11), before the wolf drops the pine cone, sniffs it and goes on. He depicts how the wolf perceives the world 'through his pads with each step [sensing] the dryness of the moss beneath his feet, and the ridges of old tracks, some his own' (11). Attuned to wolf perception and sociality, Lopez conveys the wonder of how wolf siblings recognise and locate each other through howling:

They approach each other briskly, almost formally, tails erect and moving somewhat as deer move. When they come together they make high-pitched squeaking noises and encircle each other, rubbing and pushing, poking their noses into each other's neck fur, backing away to stretch, chasing each other for a few steps, then standing quietly together, one putting a head over the other's back. And then they are gone, down a vague trail, the female first. After a few hundred yards they begin, simultaneously, to wag their tails (Lopez 2004: 12).

This description has the immediacy and authority of an eyewitness account, but it is not an exercise in control of the wolves' behaviour or readers' perceptions. The actions of the wolves are modified by some adverbs-briskly, formally, quietly, simultaneously-but neither these nor other words used are particularly associated with a value inflection. Instead, the joy of wolf siblings meeting and the synchronicity of their senses are conveyed through the closely observed actions of the wolves themselves. Subsequently, each wolf killed in what Lopez calls 'an American pogrom' (Lopez 2004: 167) is an individual, in relationships that define them.

Lopez's narrator mediates the voices of scientists and wolf hunters with magisterial control, which aligns, in this article's formulation of Derrida's account, with a benign narrative sovereignty. Alternatively, the narrative attitude of Helen Macdonald's $H$ is for hawk, a hybrid work of biography, memoir and natural history about Macdonald's relationship with her goshawk, Mabel, plays with abnegation of control. Training a goshawk to fly free, kill and return to the glove is, she writes, 'a willed loss of control ... You feel safe because you are entirely at the world's mercy. It is a rush. You lose yourself in it' (Macdonald 2014: 177). Macdonald trains Mabel while she is in shock, 
depressed and grief-stricken after the sudden death of her father. Mabel is fascinatingly Other, as well as being 'everything I wanted to be: solitary, selfpossessed, free from grief, and numb to the hurts of human life' (Macdonald 2014: 85).

Macdonald's narrative is structured by the relationship of another narrator, the author T.H. White, with his goshawk, Gos (White 1975). The competence and consistency with which Macdonald cares for Mabel are a careful rewriting of White's erratic, petulant treatment of Gos. The tension between Mabel, the captive, well-treated, calm goshawk who returns to Macdonald's fist, and Gos, the orphaned, mistreated, misunderstood hawk who flew away from White and never came back, who is free but doomed, structures the narratorial consciousness. White sabotages his relationship with Gos: he ties him with weak twine that breaks. The hawk escapes. When White writes The goshawk, he is an incompetent austringer, but Macdonald's retelling makes him an allknowing narrator: White sees Gos 'soaring over the trees in distant, expanding circles ... He can see that Gos is happy. He deserves to be free, thinks White, and wishes him well in his life in the wild. But death waits for Gos, White knows' (Macdonald 2014: 174). The cords White has attached to Gos's leg will snag on a branch and 'he will struggle, and hang, and starve, and die' (Macdonald 2014: 174). At the point of her narrative where she describes White losing his goshawk, Macdonald writes about how she becomes her goshawk. Observing Mabel, she has become more attuned to hawk sensibility:

The first few days with a wild new hawk are a delicate, reflexive dance of manners. To judge when to scratch your nose without offence, when to walk and when to sit, when to retreat and when to come close, you must read your hawk's state of mind. You do this by watching her posture and her feathers, the workings of which turn the bird's shape into an exquisitely controlled barometer of mood ... [Until] [e]ventually you don't see the hawk's body language at all. You seem to feel what it feels. Notice what it notices. The hawk's apprehension becomes your own. (Macdonald 2014: 85-6).

But a human narrator cannot remain a hawk. Mabel can see colours and movement that Macdonald cannot see; she can follow the wingbeats of a bee; she can see polarised light and into the ultraviolet spectrum; she can trace the Earth's magnetic lines of force. Her sense of time is different. Hunting with a hawk, Macdonald writes, is a 'ruinous' addiction: 'I had taken flight to a place from which I didn't want to ever return' (Macdonald 2014: 177). In this sense Macdonald becomes Gos, not Mabel. If, like Gos, she dies, her narrative will not exist. She must come back to being human. Paradoxically, it is Macdonald's recognition that '[t]he world [Mabel] lives in is not mine' (2014: 98), that animals exist in their own right, independent of humans and human assumptions, that enables her narrator to return to being human. Through becoming-hawk and unbecoming-hawk, Macdonald learns 'how you feel more human once you have known, even in your imagination, what it is like to be not' (Macdonald 2014: 275). Macdonald's narrative elucidates how '[w]ild things are made from human histories' (2014: 200), showing how goshawks are 
constructed by human narratives and how, in some contexts such as Nazi Germany, predators such as goshawks have been used to glorify human violence. In contrast to White, who calls Gos many things, including 'my lunatic from the Rhine' (1975: 102), 'a Prussian officer' and 'an Egyptian hieroglyph' (1975: 158), Macdonald's narrative is determined not to make Mabel into a figurative animal. Humans' ideas of what constitutes wildness and Mabel's instincts are different things, Macdonald writes: goshawks' 'inhumanity is to be treasured because what they do has nothing to do with us at all' (Macdonald 2014: 275). Mabel's ability to 'resist the meanings humans give her' (Macdonald 2014: 181) requires her to be alive, and relies on her narrator to be living in a 'visceral, bloody' relationship with her (Macdonald 2014: 181). Macdonald argues that if humans know animals only in mediated ways, through print or on-screen images (or, I would add, through autopsies, necropsies and government signage), or because they signify only loss-to extinction-we will be unable to learn how 'complicated', 'idiosyncratic' and 'astonishing' they are (Macdonald 2014: 181).

Emotional responses drive Lopez's and Macdonald's narratives; objectivity is not dissociated from emotion. Lopez does not call it anger, but his righteous anger reverberates from the page in his accounts of wolf killing and the rationale for wolf killing, a war enacted by humans for sovereignty over wolves' territory. Lopez's magnanimity, for both wolves and men, sets this narrative apart from simplistic, one-dimensional accounts. Macdonald's apparent abnegation and subsequent reclamation of narrative control is carefully wrought. The abyss of self-annihilation and loss-of freedom for goshawks like Gos and Mabel, of species to extinction and of her father-intensifies the acuity of her observations. Lopez and Macdonald narrate complex interspecies relationships, not with dissimulation and disingenuousness, but with sensitivity and respect for alterity.

Narrating K'gari's dingoes and the limits of knowledge

Like the Native American wolves Lopez writes about, the wongari, wat'dha and white spirit dingoes of K'gari (Dwyer 2015; Skelly 2015) are not settler Australians' dingoes. They remind us that we are in a foreign country. They unsettle our sovereignty. To convey this unsettling and the ontological uncertainty around dingoes, I sought to write about K'gari's dingoes in a way that did not impose absolutist narrative sovereignty. In addition to five in-depth interviews with people who have different knowledge bases about dingoes and how they are treated on K'gari and who offered different, sometimes conflicting, perspectives (Behrendorff 2015; Dwyer 2015; Novak 2015; Parkhurst 2015; Skelly 2015), my creative practice engagement with this field has drawn on historical narratives about shipwreck survivors and scientific papers by wildlife ecologists and ethologists, as well as my own observations, experiences and memories. Conducting interviews and analysing data, I constantly think about 
dingo subjectivity. What would a dingo make of this? What is important to dingoes? It is impossible to attain a dingo's point of view, but my source material has offered many opportunities to find common ground between people and dingoes, to tease, test and tamper with interspecies boundaries. Sadly, the opportunity to get inside a dingo's skin only came with the necropsy of the dingo whom I met on the beach. A necropsy is static. It tells me nothing of how this dingo was killed-the way he was caught, the effects of the drugs on his metabolism and the process of what happened to his body after he was killed. I have included details of his death and necropsy in my creative work because I want narrative to keep him alive. Or at least render his death as not in vain. However, Derrida's rigorous and encyclopaedic critique of the relationship between the autopsy of an animal, power, scientific knowledge and violence enables me to see that the real, ongoing, tragedy is how this dingo, and so many other animals, are objects to be disposed of: objects at the disposal of such limited knowledge.

Making any narrative, like conducting a scientific experiment, is a very human endeavour. To do so, I need to see and know as much as I can; to order and hierarchise experience and knowledge; to distil, judge, and decide what to show readers and the order in which to show it. My voice, the narrator's voice, is part of a polyvocal text, and my unconscious determines things beyond my grasp, that I may miss. Scientific, historical, anthropological and literary knowledge intertwines with my sensations, memories, assumptions and awed humility, which stems from my belief that humans have more to learn from and about dingoes. The tension between expertise and the limits of knowledge become, ideally, a productive space. The confusion of actors who do not fully understand each other might become a site of possibility, offering new ways to think about and narrate interspecies relationships.

Acknowledgment

I would like to thank $\mathrm{c}$ i n d e r 's peer reviewers and editors whose comments encouraged me to develop and clarify aspects of this essay. I am also grateful to my doctoral examiners for their insights into the narration of dingo subjectivity, interspecies boundaries and divisive subject matter in my doctoral thesis. 
Works Cited List

Allen, BL, K Higginbottom, JH Bracks, N Davies, and GS Baxter 2015 'Balancing dingo conservation with human safety on Fraser Island: the numerical and demographic effects of humane destruction of dingoes' Australian Journal of Environmental Management 22 (2), 197-215, doi.org/10.1080/14486563.2014.999134

Balme, J and S O'Connor 2016 'Dingoes and Aboriginal social organisation in Holocene Australia', Journal of Archaeological Science: Reports 7, 775-81, doi: org/10.1016/j.jasrep.2015.08.015

Behrendorff, L 2015 Interview with author, Eurong QLD, 26 November

Behrendorff, L and BL Allen 2016 'From den to dust: longevity of three dingoes (Canis lupus dingo) on Fraser Island (K'gari)' Australian Mammalogy 38 (2), 256-60, doi: 10.1071/AM17024

Carter, J, A Wardell-Johnson, and C Archer-Lean 2017 'Butchulla perspectives on dingo displacement and agency at K'gari-Fraser Island, Australia' Geoforum 85, 197-205, doi: http://dx.doi.org/10.1016/j.geoforum.2017.08.001.

Despret, V 2016 [2012] What would animals say if we asked the right questions? B Buchanan (trans.) Ninneapolis and London: University of Minnesota Press.

Derrida, J 2009 The beast and the sovereign: volume $1 \mathrm{G}$ Bennington (trans.) Chicargo: University of Chicago Press.

Dwyer, F 2015 Interview with author, Hervey Bay QLD, 27 November

Donaldson, S and W Kymlicka 2016 'Between wildness and domestication: rethinking categories and boundaries in response to animal agency' in B Bovenkerk and J Keulartz (eds) Animal ethics in the age of humans: blurring boundaries in human-animal relationships New York: Springer, 224-239.

Ecosure 2012 'Fraser Island Dingo Management Strategy Review’ report to Queensland Department of Environment and Heritage Protection, West Burleigh QLD.

Ecosure 2013 'Fraser Island Dingo Conservation and Risk Management Strategy', Queensland Department of Environment and Heritage Protection, at https://www.ehp.qld.gov.au/wildlife/livingwith/dingoes/pdf/dingomanagement-strategy.pdf (accessed 6 April 2016).

Foucault, M 1995 Discipline and punish: the birth of the prison 2nd edn A Sheridan (trans.), New York: Vintage.

Hamilton, A 1972 ‘Aboriginal man’s best friend?’ Mankind 8 (4), 287-95.

Keane, J 2014 'Antarctica: notes on the fate of sovereignty' The Conversation 24 June, at https://theconversation.com/antarctica-notes-on-the-fateof-sovereignty-28292 (accessed 12 March 2019). 
Lennox, R 2013a 'Head of a dog' Southerly 73 (3), 212-26.

Lennox, R 2013b 'What I'm reading' Meanjin blog 2 December 2013, at https://meanjin.com.au/blog/what-im-reading-rowena-lennox/ (accessed 12 March 2019)

Lennox, R 2014 ‘Apex predators’, Meanjin 73 (3): 6-9

Lennox, R 2016 'Coolooloi' Authorised Theft: writing, scholarship, collaboration, refereed proceedings of the 21st conference of the Australasian Association of Writing Programs, Canberra, at http://www.aawp.org.au/wpcontent/uploads/2017/03/Lennox AAWP 2016 Coolooloi.pdf. (accessed 12 March 2019)

Lennox, R 2017 'Killing Bold: managing the dingoes of Fraser Island' Griffith Review 57, 255-70, at https://griffithreview.com/articles/killing-boldmanaging-the-dingoes-of-fraser-island/ (accessed 12 March 2019)

Lennox, R 2019a 'Incessant: K'gari's dingoes and Fraser Island contact history' in Gillian Dooley and Danielle Clode (eds) The First Wave: exploring early coastal contact history in Australia Adelaide: Wakefield Press.

Lennox, R forthcoming Bold: ingenious dingoes of K'gari Sydney: Sydney University Press.

Lopez, B 2004 [1978] Of wolves and men New York: Scribner.

Macdonald, H 2014 H is for hawk London: Jonathan Cape.

Novak, D 2015 Interview with author, Eurong QLD, 26 November

Parker, MA 2006, 'Bringing the dingo home: discursive representations of the dingo by Aboriginal, colonial and contemporary Australians' PhD thesis, School of English, Journalism and European Languages, University of Tasmania.

Parkhurst, J 2015 Interview with author, Rainbow Beach and K'gari QLD, 1819 May

Philip, J 2017 'Representing the dingo: an examination of dingo-human encounters in Australian cultural and environmental heritage' $\mathrm{PhD}$ thesis, School of Ecosystem Management, Armidale: University of New England.

Probyn-Rapsey, F 2015 'Dingoes and dog-whistling: a cultural politics of race and species in Australia' Animal Studies Journal 4 (2), 55-77, at http://ro.uow.edu.au/asj/vol4/iss2/4 (accessed 27 June 2018).

Rimmon-Kenan, S 1983 Narrative fiction: contemporary poetics London: Methuen

Rose, DB 2000 [1992] Dingo makes us human: life and land in Australian Aboriginal culture Cambridge: Cambridge University Press

Rose, DB 2011 Wild dog dreaming: love and extinction Charlottesville \& London: University of Virginia Press. 
Queensland government 2014 Department of Environment and Science, About Fraser Island dingoes, Dingo management on Fraser Island, Fraser Island Dingo Conservation and Risk Management Strategy, at https://parks.des.qld.gov.au/parks/fraser/dingo-management.html (accessed 5 March 2019)

Queensland government 2017-2018 Department of National Parks, Sport and Racing - disclosure log entries, Department of Environment and Science, at https://www.des.qld.gov.au/ourdepartment/rti/disclosure-log/npsr/ (accessed 19 November 2018)

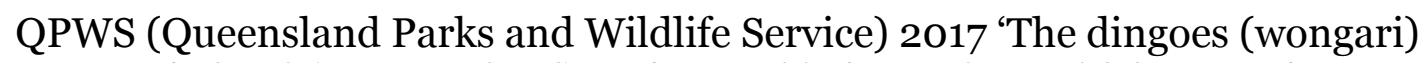
of K'gari (Fraser Island): safety and information guide' State of Queensland, Department of National Parks, Sport and Racing, at https://parks.des.qld.gov.au/parks/fraser/pdf/be-dingo-safe-flyer.pdf (accessed 17 December 2018)

Skelly, K 2015 Interview with author, Hervey Bay QLD, 25 November

Wadiwel, D 2010 'A human right to stupidity: review of Jacques Derrida, The beast and the sovereign vol. 1', Borderlands e-journal, 9 (3), at http://www.borderlands.net.au/volgno3 2010/wadiwel derrida.pdf (accessed 12 March 2019).

White, TH 1975 [1951] The goshawk Harmondsworth: Penguin. 